\title{
DROUGHT TOLERANCE AND SUSCEPTIBILITY OF MAIZE (ZEA MAYS L.) USING YIELD RESPONSE FACTOR AND TOLERANCE INDICES
}

\author{
HAMA, B. M. - MOHAMMED, A. A. \\ Crop Science Department, College of Agricultural Sciences, University of Sulaimani, \\ Sulaimani, Kurdistan Region, Iraq \\ (e-mail: bekhal.mustafa@univsul.edu.iq; phone: +964-770-190-0487) \\ *Corresponding author \\ e-mail: aram.muhammed@univsul.edu.iq; phone: +964-770-157-6760 \\ (Received 26 $6^{\text {th }}$ Mar 2019; accepted $13^{\text {th }}$ Jun 2019)
}

\begin{abstract}
In order to evaluate the drought tolerance and susceptibility of six maize hybrids under water deficit conditions, an investigation was conducted during the growing season of 2016 at the Qlyasan Research station- University of Sulaimani. The field experiment was implemented according to the split plot design with three replications, four different irrigation levels were allocated in main plots, while six maize (Zea mays L.) hybrids were cultivated in the sub-plots. The yield response factor (Ky) was estimated through calculating adjusted crop coefficient (Ks) as well as adjusted Crop evapotranspiration (ETc adj.) in growth stages, including initial, rapid growth, mid-season, and the late season, revealing Ks values lower than that obtained by FAO paper No.33, $(0.49,0.6,0.528$, and 0.204$)$ respectively. Four stress tolerance indices, including stress tolerance index (STI), stress tolerance (TOL), mean productivity (MP),) and geometric mean productivity (GMP) were used in this study. Data analysis demonstrated that the indices STI, TOL, MP, and GMP were more effective in defining the high yielding hybrids under different growing conditions. The results of the cluster analysis, yield response factor (Ky) and stress indices corresponded due to tolerance and susceptibility of maize hybrids.
\end{abstract}

Keywords: water deficit, resistance, sensibility, maize hybrid

\section{Introduction}

Maize (Zea mays L.) is considered as the third most important cereal crop after wheat and rice around the world, it covers $4.8 \%$ of the total cropped area and attributes $3.5 \%$ of the global agricultural crop output (Ahmad et al., 2011; Deryng et al., 2014). Some of the challenges that influence the productivity and the expansion of the maize cultivation in a semiarid region are caused by water deficit and shortage in water availability, the yield of different crops reaches the maximum value with evapotranspiration (ETm), therefore an actual yield (Ya) matches with an actual evapotranspiration (ETa) (Nacharchi et al., 2011). Drought tolerance consists of ability of crop for growth and production under water deficit conditions. A long-term drought stress effects on plant metabolic reactions associates with, plant growth stage, water storage capacity of the soil and physiological aspects of plant. Crop response to the limited water condition is important for adjusting the relationship between grain yield and efficient irrigation systems to evaluate crop performance under water deficit condition (Carvalho et al., 2016; Irandoust and Bijanzadeh, 2017).

The yield response factor $(\mathrm{Ky})$ is a factor that describes the reduction in relative yield according to the reduction in ETc caused by a soil water shortage, the response of a crop to its soil moisture environment is quantified through Ky (Greaves and Wang, 2017), the values of Ky are crop specific and may vary over the growing season (Steduto et al., 2012). Usually, the decrease in yield due to water deficit during the vegetative and 
ripening period is relatively small, while during the flowering and yield formation periods it will be large. Values for Ky for individual growth periods and for the complete growing season have been included in the FAO Irrigation and Drainage Paper No 33. The importance of the yield response factor is to determine the efficiency of water use and crop productivity, which is founded on the relative yield loss of any crop to the relative reduction of water requirements, differences in actual evapotranspiration and the crop response factor which usually vary according to crop growing conditions. The average Ky value founded by previous researchers (Najarchi et al., 2011) was higher than the previous reported values, thus, the reductions in yield under effect of deficit irrigation are higher than those reported by FAO (Doorenbos and Kassam, 1979). Enormous distinction of Ky value for maize resulted from variation in environmental effects and growth patterns were represented in the previous research, there was deviation from finding of Doorenbos and Kassam (1979), whom they determined ky value for maize 1.25, while other researchers documented 2.15 for sensitive genotypes and 1.56 for water deficit resistance genotypes, as well the different values of ky 1.58 and 1.50 were showed with stress condition at tasseling or silking and post silking stage, however the ky value for those growing stages were $0.40,1.50$, and 0.50 found by Doorenbos and Kassam (1979).

Drought indices clarify the effect of drought on the yield forfeiture comparing with the yield under no stress condition has been used for drought tolerance checking (Mitra,2001). To evaluate response of plant genotypes to drought stress, some selection indices based on a mathematical relation between stress- and optimum conditions has been proposed. Moghaddam et al. (2002) found Stress Tolerant Index (STI) was more useful in order to select favourable corn cultivars under stressful and stress-free conditions, however the greater TOL value indicate to larger grain yield reduction under stress condition, whereas lowest TOL indicate to lower grain yield reduction under stress condition. Khalili et al. (2004) showed that based on Geometric Mean Productivity (GMP) and STI indices, corn hybrids with high yield in both stress and non-stress environments can be selected. Talebi et al. (2009) concluded that GMP and STI were able to discriminate tolerant genotypes under stress conditions, their results indicated that there was a positive and significant correlation among Yp and (MP, GMP and STI) and Ys and (MP, GMP and STI) and they hence were better predictors of Yp and Ys than TOL. There was indication of significant correlation between MP, STI, and GMP with the yield at both non-stress and stress conditions (Zare, 2012).

Thus, the objective of this study was the evaluation of yield response factor and the efficiency and profitability of different selection indices in the identification of maize hybrids, which are compatible with stressful and optimal conditions, to achieve hybrids that can tolerate water deficit condition especially at sensitive growth stages.

\section{Materials and methods}

Six maize hybrids were evaluated in the investigation includes Medium 791, Btaris, Cantabpis, Fajr 260, Es-Solito 655, and Dhqan. All hybrids were produced from College of Agriculture, the University of Kurdistan, Sianandaj-Iran. The study was conducted during the summer season of 2016 at the Qlyasan Research Station, College of Agricultural Sciences, University of Sulaimani/KRG-Iraq (35 $34^{\circ}$ '19' N $45^{\circ} 22^{\prime}$ 1.6" E with altitude of 754 m.a.s.l). The experiment was laid out in a split plot design in which water deficit levels will be in the main plots and each treatment was replicated 
three times. Each replication was divided into four main plots with different schedules irrigation. The six hybrids were randomly distributed within the sub-plots. Four irrigation treatments were used as well Irrigation $\left(\mathrm{I}_{1}\right)$, deficit irrigation during the vegetative period $\left(\mathrm{I}_{2}\right)$, reproductive period $\left(\mathrm{I}_{3}\right)$ and both of them $\left(\mathrm{I}_{4}\right)$. A net plot size of $4 \mathrm{~m} \times 10.2 \mathrm{~m}$ was kept. The crop was sown during the first week of Jully in rows $70 \mathrm{~cm}$ apart and $25 \mathrm{~cm}$ between plants. In order to prevent the lateral spread of water plots a distance of $2 \mathrm{~m}$ between plots was left bare. Phosphorus fertilizer, as triple super phosphate, was applied before sowing time with rate of $150 \mathrm{~kg} \mathrm{ha}^{-1}$. The nitrogen fertilizer, as urea $46 \% \mathrm{~N}$, was applied by two doses, the first one was applied at the seedling stage and the second application was on tasseling stage. All other agricultural practices were behaving as required. The yield response factor $(\mathrm{Ky})$ was calculated, for determining the responses of maize hybrids to the effect of water deficit, a simple, linear crop-water production function was introduced in the FAO Irrigation and Drainage Paper No 33 (Steduto et al., 2012) to predict the reduction in crop yield when crop stress was caused by a shortage of soil water:

$$
\left[1-\frac{Y a}{Y m}\right]=K y\left[1-\left(\frac{E T c a d j}{E T c}\right)\right]
$$

Where: $\mathrm{Ya}=$ actual yield of the crop $\left[\right.$ ton $\left.\mathrm{ha}^{-1}\right], \mathrm{Ym}=$ maximum (expected) yield in the absence of environmental or water stress [ton ha- $\left.{ }^{-1}\right], \mathrm{Ky}=\mathrm{a}$ yield response factor [-], ETc adj = adjusted (actual) crop evapotranspiration $\left[\begin{array}{lll}\mathrm{mm}^{-1} & \mathrm{~d}^{-1}, \quad \mathrm{ETc}=\mathrm{crop}\end{array}\right.$ evapotranspiration for standard conditions (no water stress) [ $\left.\mathrm{mm} \mathrm{d}^{-1}\right]$.

In the crop coefficient approach the crop evapotranspiration, ETc, is calculated by multiplying the reference crop evapotranspiration, ETo, by a crop coefficient, Kc The adjusted Crop Coefficient, or stress, crop coefficient (Ks) which describes the effect of water stress on crop transpiration was quantified for determining the exact effect of the soil water stress on the crop transpiration in water deficit treatments, the incorporation of the effect of water stress into crop coefficient $(\mathrm{Kc})$ was determined as:

$$
\text { ETc adj }=K s \times E t c
$$

Where is the $=$ stress, crop coefficient [dimensionless], Etc $=$ crop evapotranspiration [mm $\left.\mathrm{d}^{-1}\right]$.

$$
E T c=K c \times E T o
$$

Where $\mathrm{Kc}=$ crop coefficient $[$ dimensionless $]$, ETo $=$ reference evapotranspiration $\left[\mathrm{mm}^{-1}\right]$.

$$
\begin{gathered}
E T o=P(0.46 \times \text { Tmean }+8) \\
K s=(T A W-D r) /(T A W-R A W)
\end{gathered}
$$

Where TAW $=$ the total available soil water in the root zone $[\mathrm{mm}], \mathrm{RAW}=$ the readily available soil water in the root zone [mm], Dr = root zone depletion [mm].

$$
T A W=1000(\theta F . C-\theta W . P) Z r
$$


Where $\theta \mathrm{F} . \mathrm{C}=$ the water content at field capacity $\left[\mathrm{m}^{3} \mathrm{~m}^{-3}\right], \theta \mathrm{W} \cdot \mathrm{P}=$ the water content at wilting point $\left[\mathrm{m}^{3} \mathrm{~m}^{-3}\right], \mathrm{Zr}=$ the rooting depth $[\mathrm{m}]$.

$$
\operatorname{Dr}=1000(\theta F . C-\theta i-1) Z r
$$

Where $\theta \mathrm{i}-1=$ the average soil, water content for the effective root zone [mm].

$$
R A W=p \times T A W
$$

Where $\mathrm{p}=$ average fraction of Total Available Soil Water (TAW) that can be depleted from the root zone before moisture stress.

The studied drought resistance indices were calculated by using the following relationships in Table 1:

Table 1. The computing relations of the parameters studied in the experiment

\begin{tabular}{c|c|c}
\hline Parameters & Formula & Reference \\
\hline Stress Tolerance Index (STI) & STI $=$ Ypi $\times$ YsiYp & Fernandez, 1992 \\
Tolerance Index (TOL) & TOL $=$ Ypi - Ysi & Rosielle and Hamblin, 1981 \\
Geometric Mean Productivity (GMP) & GMP = Ypi $\times$ Ysi & Fernandez, 1992 \\
Mean Productivity (MP) & MP = Ypi + Ysi2 & Rosielle and Hamblin, 1981 \\
\hline
\end{tabular}

Ysi = yield of hybrid in stress condition, Ypi = yield of hybrid in normal condition And SI that is stress intensity, where: $\mathrm{SI}=[1-\mathrm{YsYp}]$. Ys $=$ total yield mean in stress condition, $\mathrm{Yp}=$ total yield mean in normal condition

The software JMP version 13 and XLSTAT version 16 were used for statistical analysis like one-way analysis of variance and LSD test at the 5\% level. The principal component analysis (PCA) Eriksson et al. (1999) was determined to assess the relationship between the variables. Depending on the means of stress indices characters, the dendrogram was produced by using the Euclidean distances and unweighted pairgroup method with the arithmetic mean (UPGMA) analysis method.

\section{Results and discussion}

Water stress may be induced under the effect of lower water supply and the evapotranspiration will drop below the standard crop evapotranspiration, ETc., The reduction in the value of crop coefficients under water deficit conditions is determined using the stress crop coefficient Ks (calculated with Eq. 5). Table 1 demonstrates the adjusted crop evapotranspiration ETc adj. (Calculated with the Eq. 2) For water deficit treatments include $\mathrm{I}_{2}, \mathrm{I}_{3}$, and $\mathrm{I}_{4}$ as well adjusted crop coefficient (Ks x Kc), because the modification of vegetation and ground cover mean that the crop coefficient Kc varies during the growing period as well with influence of water deficit levels (Payero et al., 2008; Allen et al., 2017). In order to determining the yield response factor of maize hybrids under influence of well irrigation as well water deficit levels, the adjusted evapotranspiration was used, the stress crop coefficient that calculated for different growth stages of six maize hybrids were declined from 0.7 , to 0.49 , for irrigation levels, $\mathrm{I}_{2}, \mathrm{I}_{3}$, and $\mathrm{I}_{4}$ respectively during initial stage, and from 1.2 , to 0.6 , for rapid growth stage and from 1.2 , to 0.528 , for mid season stage and for the late season stage it declined from 0.6 to 0.204 . The calculation of adjusted evapotranspiration was done in 
accordance with adjusted $\mathrm{Kc}(\mathrm{Kc} \mathrm{x} \mathrm{Ks})$. The adjusted crop evapotranspirations were used in calculating the yield response factor Ky of the maize hybrids in different growth stages and demonstrated in Table 2, the variation between adjusted evapotranspiration and actual evapotranspiration has created under influence of higher reference evapotranspiration, similar results were documented by (Kuscu et al., 2013).

Table 2. Adjusted crop coefficient and adjusted crop evapotranspiration in different growth stages

\begin{tabular}{|c|c|c|c|c|c|c|c|c|c|c|c|c|}
\hline $\begin{array}{c}\text { Growth } \\
\text { stages }\end{array}$ & I. $\mathbf{T}$. & T. min & T. $\max$ & T. mean & ETo & Kc & ETc & TAW & RAW & Dr & $\mathrm{Ke} \times \mathrm{Ks}$ & ETc adj. \\
\hline \multirow{4}{*}{ Initial } & I1 & \multirow{4}{*}{35.6} & \multirow{4}{*}{43.63} & \multirow{4}{*}{39.615} & \multirow{4}{*}{8.39} & \multirow{4}{*}{0.7} & \multirow{4}{*}{5.873} & \multirow{4}{*}{32.04} & \multirow{4}{*}{17.622} & 12.93 & 0.7 & 5.873 \\
\hline & $\mathrm{I} 2$ & & & & & & & & & 21.72 & 0.49 & 4.1111 \\
\hline & I3 & & & & & & & & & 12.93 & 0.7 & 5.873 \\
\hline & I4 & & & & & & & & & 21.72 & 0.49 & 4.1111 \\
\hline \multirow{4}{*}{$\begin{array}{l}\text { Rapid } \\
\text { growth }\end{array}$} & I1 & \multirow{4}{*}{35.62} & \multirow{4}{*}{43.88} & \multirow{4}{*}{39.75} & \multirow{4}{*}{7.62} & \multirow{4}{*}{1.2} & \multirow{4}{*}{9.144} & \multirow{4}{*}{75.25} & \multirow{4}{*}{22.575} & 22.54 & 1.2 & 9.144 \\
\hline & I2 & & & & & & & & & 48.37 & 0.6 & 4.572 \\
\hline & I3 & & & & & & & & & 22.54 & 1.2 & 9.144 \\
\hline & I4 & & & & & & & & & 48.37 & 0.6 & 4.572 \\
\hline \multirow{4}{*}{$\begin{array}{c}\text { Mid- } \\
\text { season }\end{array}$} & I1 & \multirow{4}{*}{24.72} & \multirow{4}{*}{33.24} & \multirow{4}{*}{28.98} & \multirow{4}{*}{5.65} & \multirow{4}{*}{1.2} & \multirow{4}{*}{6.78} & \multirow{4}{*}{134.4} & \multirow{4}{*}{73.91} & 70.25 & 1.2 & 6.78 \\
\hline & I2 & & & & & & & & & 70.25 & 1.2 & 6.78 \\
\hline & I3 & & & & & & & & & 107.25 & 0.528 & 2.9832 \\
\hline & I4 & & & & & & & & & 107.25 & 0.528 & 2.9832 \\
\hline \multirow{4}{*}{$\begin{array}{l}\text { Late- } \\
\text { season }\end{array}$} & I1 & \multirow{4}{*}{17.34} & \multirow{4}{*}{26.13} & \multirow{4}{*}{21.74} & \multirow{4}{*}{4.14} & \multirow{4}{*}{0.6} & \multirow{4}{*}{2.484} & & & 73.625 & 0.6 & 2.484 \\
\hline & I2 & & & & & & & 1344 & 7391 & 73.625 & 0.6 & 2.484 \\
\hline & $\mathrm{I} 3$ & & & & & & & 134.4 & 15.91 & 113.625 & 0.204 & 0.8446 \\
\hline & I4 & & & & & & & & & 113.625 & 0.204 & 0.8446 \\
\hline
\end{tabular}

I.T.: irrigation treatment, T.min: minimum temperature, T.max: maximum temperature, T.mean: mean of temperature, ETo: reference evapotranspiration, Kc: crop coefficient, ETc: crop evapotranspiration, TAW: total available soil water in the root zone, RAW: readily available soil water in the root zone, $\mathrm{Dr}=$ root zone depletion, Ks: stress crop coefficient, ETc adj: adjusted crop evapotranspiration

\section{Yield response factor $(\mathrm{Ky})$}

The effect of water deficit levels represented as $\mathrm{I}_{1}, \mathrm{I}_{2}, \mathrm{I}_{3}$, and $\mathrm{I}_{4}$ on the kernel yield of six maize hybrids indicated to decrease in yield with decreasing the water availability, there were variation in the values of yield response factor Ky which indicate to the sensitivity of maize to water stress, and there were differences in the effect of water deficit between the growth stages across the growing season (Dijaman et al., 2013). Table 3 demonstrate the values of Ky of six maize hybrids in four growth stages include initial stage, rapid growth stage, mid-season stage, and the late season stage, the schedule of the water deficit treatments was varied according to the severity of the water shortage as well the sensitivity of the growth stages, the water deficit treatment during the initial and rapid growth stages were with $\mathrm{I}_{2}$ and $\mathrm{I}_{4}$ only, the response of all maize hybrids through Ky values under effect of $\mathrm{I}_{2}$ were greater than 1 except the hybrids $\mathrm{H}_{3}$ and $\mathrm{H}_{4}$ showing (0.843 and 0.616) respectively, demonstrating less sensitivity to water deficit decrease, while Ky of all hybrids were indicated to greater values with the influence of $\mathrm{I}_{4}$ than that was obtained with the effect of $\mathrm{I}_{2}$ by $(24.226 \%$, $30.8 \%, 44.5 \%, 42.6 \%, 28.8 \%$, and $28.8 \%)$ for $\left(\mathrm{H}_{1}, \mathrm{H} 2, \mathrm{H} 3, \mathrm{H}_{4}, \mathrm{H}_{5}\right.$, and $\left.\mathrm{H}_{6}\right)$ respectively, demonstrating the greater effect of the water deficit condition created with 
the effect of $\mathrm{I}_{4}$ due to decreasing in the kernel yield of six maize hybrids, the most sensitive hybrid in initial and rapid growth stages was shown with response of $\mathrm{H}_{5}$, showed Ky value of 1.653 and 2.32. The Ky value of all hybrids during the mid season with the influence of the levels $\mathrm{I}_{3}$ and $\mathrm{I}_{4}$, the comparative between the Ky value in this stage of tasseling and silking which is sensitive to stress and that obtained by FAO was greater with variation between maize hybrids that expanded from 0.472 of $^{\mathrm{H}_{3}}$ to 1.306 for H6, Ky values of all hybrids in the late season under the impact of the $\mathrm{I}_{4}$ level revealed a higher sensitivity of maize hybrids except the hybrid $\mathrm{H}_{4}$, in the late season the lower values of Ky were taken out for all hybrids with the effect of $\mathrm{I}_{3}$ and $\mathrm{I}_{4}$ with specificity to $\mathrm{H}_{3}$ and $\mathrm{H}_{4}$ that they manifested Ky values $(0.4,0.65$ and $0.469,0.487)$ respectively, the results of late season were close to the finding of Doorenbos and Kassam (1979). The higher water potential of the air during the growing season of maize in the region resulted the differences of Ky value in comparison with the finding of previous researchers include that obtained by FAO are in agreement with results of Doorenbos and Kassam (1994), Dagdelen et al. (2005), Mengu and Ozgurel (2008) and Najrachi et al. (2011).

Table 3. Yield response fractions for six hybrids in four growth stages under stress and nonstress conditions

\begin{tabular}{c|c|c|c|c|c}
\hline Growth stages & Hybrids & $\mathbf{I}_{\mathbf{1}}$ & $\mathbf{I}_{2}$ & $\mathbf{I}_{\mathbf{3}}$ & $\mathbf{I}_{\mathbf{4}}$ \\
\hline & $\mathrm{H}_{1}$ & - & 1.47 & - & 1.94 \\
& $\mathrm{H}_{2}$ & - & 1.323 & - & 1.913 \\
Initial growth stage $\mathrm{I}_{1}$ \& $\mathrm{I}_{3}$ : no stress $\mathrm{I}_{2}$ \& $\mathrm{I}_{4}$ : stress & $\mathrm{H}_{3}$ & - & 0.843 & - & 1.52 \\
& $\mathrm{H}_{4}$ & - & 0.616 & - & 1.073 \\
& $\mathrm{H}_{5}$ & - & 1.653 & - & 2.32 \\
& $\mathrm{H}_{6}$ & - & 1.443 & - & 2.026 \\
\hline & $\mathrm{H}_{1}$ & - & 0.882 & - & 1.164 \\
Rapid growth stage $\mathrm{I}_{1}$ \& $\mathrm{I}_{3}$ : no stress $\mathrm{I}_{2}$ \& $\mathrm{I}_{4}$ : stress & $\mathrm{H}_{2}$ & - & 0.794 & - & 1.148 \\
& $\mathrm{H}_{3}$ & - & 0.506 & - & 0.912 \\
& $\mathrm{H}_{4}$ & - & 0.37 & - & 0.644 \\
& $\mathrm{H}_{5}$ & - & 0.992 & - & 1.392 \\
& $\mathrm{H}_{6}$ & - & 0.866 & - & 1.216 \\
\hline & $\mathrm{H}_{1}$ & - & - & 0.896 & 1.041 \\
Mid-season growth stage $\mathrm{I}_{1}$ \& $\mathrm{I}_{2}$ : no stress $\mathrm{I}_{3}$ \& $\mathrm{I}_{4}$ : stress & $\mathrm{H}_{2}$ & - & - & 0.862 & 1.026 \\
& $\mathrm{H}_{3}$ & - & - & 0.472 & 0.815 \\
& $\mathrm{H}_{4}$ & - & - & 0.767 & 0.576 \\
& $\mathrm{H}_{5}$ & - & - & 1.017 & 1.245 \\
& $\mathrm{H}_{6}$ & - & - & 1.305 & 1.087 \\
\hline & $\mathrm{H}_{1}$ & - & - & 0.759 & 0.881 \\
& $\mathrm{H}_{2}$ & - & - & 0.73 & 0.869 \\
& $\mathrm{H}_{3}$ & - & - & 0.4 & 0.69 \\
& $\mathrm{H}_{4}$ & - & - & 0.65 & 0.487 \\
& $\mathrm{H}_{5}$ & & & 0.862 & 1.054 \\
& $\mathrm{H}_{6}$ & & & 1.106 & 0.921 \\
\hline
\end{tabular}

According to the irrigation schedule used in the study, the $\mathrm{I}_{1}$ represented well irrigation in all growth stages, $\mathrm{I}_{3}$ performed water stress in reproductive stage only (mid and late season), while $\mathrm{I}_{2}$ caused water stress during the initial and rapid stages, and $\mathrm{I}_{4}$ exemplified water stress in all growth stages 


\section{Stress indices}

The results of analyses of variance demonstrated significant differences among maize hybrids for kernel yield under well irrigation and water stress conditions (YPi and Ysi) and for the investigated drought related indices which were presented in Table 4. High yield value in non-stress (Ypi) and stress conditions (Ysi) was exhibited by hybrid Medium 791, displaying (7.267 ton $\mathrm{ha}^{-1}$ ) and (4.058 ton ha- ${ }^{-1}$ ) respectively. While low yield value in non-stress and stress conditions was exhibited by hybrids Fajr 260 with (2.748 ton $\left.\mathrm{ha}^{-1}\right)$ and Dhqan (1.044 ton $\mathrm{ha}^{-1}$ ) respectively. The maximum value of STI (1.633), MP (5.662) and GMP (5.370) indices was by hybrid Medium 791. In addition, the highest value for TOL (3.641 ton $\mathrm{ha}^{-1}$ ) was from hybrid Medium 791. Thus, the hybrid Medium 791 had a desirable yield in all conditions and hence it is recommendable in a semiarid conditions, results are similar to that obtained by previous researchers as Rosielle and Humblin (1981), Fernandez (1992) and Dijaman et al. (2013).

Table 4. Means and selection indices for grain yield (ton $\mathrm{ha}^{-1}$ ) of six maize hybrids evaluated under stress and non-stress condition

\begin{tabular}{|c|c|c|c|c|c|c|c|c|}
\hline Hybrids & Ypi & Ysi1 & Ysi2 & Ysi3 & STI & TOL & MP & GMP \\
\hline \multirow{3}{*}{ Medium 791} & 7.27 & 4.058 & \multirow{3}{*}{3.625} & & 1.633 & 3.208 & 5.662 & 5.37 \\
\hline & & & & & 1.451 & 3.641 & 5.445 & 4.916 \\
\hline & & & & 3.035 & 1.193 & 4.231 & 5.15 & 4.448 \\
\hline \multirow{3}{*}{ Btaris } & 4.36 & 2.629 & \multirow{3}{*}{2.256} & & 0.642 & 1.733 & 3.495 & 3.305 \\
\hline & & & & & 0.559 & 2.105 & 4.519 & 3.048 \\
\hline & & & & 1.856 & 0.425 & 2.505 & 3.109 & 2.641 \\
\hline \multirow{3}{*}{ Cantabpis } & 2.88 & 2.152 & \multirow{3}{*}{2.118} & & 0.347 & 0.728 & 2.516 & 2.482 \\
\hline & & & & & 0.341 & 0.762 & 2.499 & 2.463 \\
\hline & & & & 1.567 & 0.25 & 1.314 & 2.223 & 2.083 \\
\hline \multirow{3}{*}{ Fajr 260} & 2.75 & 2.237 & \multirow{3}{*}{1.568} & & 0.342 & 0.51 & 2.492 & 2.475 \\
\hline & & & & & 0.236 & 1.18 & 2.158 & 2.074 \\
\hline & & & & 1.861 & 0.285 & 0.887 & 2.304 & 2.253 \\
\hline \multirow{3}{*}{ Es-Solito 655} & 4.44 & 2.527 & \multirow{3}{*}{1.912} & & 0.644 & 1.913 & 3.483 & 3.315 \\
\hline & & & & & 0.481 & 2.528 & 3.176 & 2.899 \\
\hline & & & & 1.347 & 0.319 & 3.093 & 2.893 & 2.381 \\
\hline \multirow{3}{*}{ Dhqan } & 3.87 & 2.192 & \multirow{3}{*}{1.044} & & 0.481 & 1.675 & 3.028 & 2.854 \\
\hline & & & & & 0.217 & 2.822 & 2.455 & 1.977 \\
\hline & & & & 1.513 & 0.314 & 2.353 & 2.689 & 2.314 \\
\hline
\end{tabular}

Ypi: Yield of a given hybrid in optimal conditions. Ysi1: Yield of a given hybrid in stress conditions (in vegetative period). Ysi2: Yield of a given hybrid in stress conditions (in reproductive period). Ysi3: Yield of a given hybrid in stress conditions (in vegetative \& reproductive period). STI: stress tolerance index. TOL: tolerance index. MP: mean productivity. GMP: geometric mean productivity

The results of analyses of variance for the investigated drought related indices were presented in Table 5. Significant differences were found for all stress indices, The performance of six maize hybrids with stress indices showed significant differences among all hybrids that evaluated under stress and non-stress conditions. The $\mathrm{H}_{1}$ showed the highest value of STI with 1.426 indicating to high yield potential and higher stress tolerance, and minimum value of $\mathrm{H}_{4}$ Fajr260 was 0.288 , the highest value of TOL was obtained by $\mathrm{H}_{1}$ (medium 791) revealing 3.694 demonstrating greater reduction in grain yield under water deficit condition, while the minimum value of TOL manifested with 
$\mathrm{H}_{3}$ and $\mathrm{H} 4$ (0.935 and 0.859$)$ indicating to a lesser reduction in grain yield. The higher values of MP and GMP showed by $\mathrm{H}_{1}$ demonstrate high correlation between these indices and the yield. The results were similar to that documented by Papathanasiou et al. (2015).

Table 5. Mean value for selection indices of six maize hybrids evaluated under stress and non-stress condition

\begin{tabular}{c|c|c|c|c}
\hline Hybrids & STI & TOL & MP & GMP \\
\hline Medium 791 & 1.426 & 3.694 & 5.419 & 4.911 \\
Btaris & 0.542 & 2.114 & 3.707 & 2.998 \\
Cantabpis & 0.313 & 0.935 & 2.413 & 2.343 \\
Fajr 260 & 0.288 & 0.859 & 2.318 & 2.267 \\
Es-Solito 655 & 0.481 & 2.511 & 3.184 & 2.865 \\
Dhqan & 0.337 & 2.283 & 2.724 & 2.381 \\
LSD (P $\leq 0.05)$ & 0.297 & 0.949 & 0.689 & 0.656 \\
\hline
\end{tabular}

The biplot analysis (Fig. 1) is required to identify the best performance hybrids for both stress and non-stress conditions. The principle component analysis (PCA) converts the variables to the independent combinations. These principle components formed $100 \%$ of the total variation among maize hybrids. The two principal components PC1 and PC2 revealed $99.40 \%$ of the original phenotypic variation. The value of the contribution of first and second components was 94.29 and $5.11 \%$, respectively. Regarding the distribution of indices and hybrids on PCA plot, the indices or hybrids that were subsisting away from the centre of the plot in the positive trends of distinct traits demonstrated their best performance, whereas; the indices or hybrids that were out most from the centre of the plot in the negative orientation of traits displayed their weak performance (Fig. 1). The most important component, PC1, was positively and negatively influenced by indices: STI, MP, GMP, and TOL. The second PCA accounted for $5.11 \%$ of all variations. The maize hybrids showed a wide variability in phenotypic traits among them. Four groups of maize hybrids with different genetic constituents were highlighted on scatter plot: the first group composed of $\mathrm{H}_{1}$. The second group included $\mathrm{H}_{2}$ and the third group composed $\mathrm{H}_{3}$ and $\mathrm{H}_{4}$, whereas the fourth groups contained $\mathrm{H}_{5}$ and $\mathrm{H}_{6}$, respectively. On the other hand, the results of some stress indices (STI, GMP, MP, and YI) for $\mathrm{H}_{1}$ hybrid were opposite to those recorded for $\mathrm{H}_{6}$ hybrid. As shown in PCA biplot, the highest values of GMP, MP, STI and YI were recorded by $\mathrm{H}_{1}$ hybrid signalizing that genotypes with larger PCA1 and lower PCA2 scores gave high yields (Darvishzadeh et al., 2010; Khodarahmpour et al., 2011). This result indicates that $\mathrm{H}_{1}$ hybrid was the most tolerant hybrid, whereas, the hybrids: $\mathrm{H}_{5}$ and $\mathrm{H}_{6}$ were the most susceptible hybrids. $\mathrm{H}_{3}$ and $\mathrm{H}_{4}$ hybrids shared common indices.

Cluster analysis for the six maize hybrids was behaving to identify a cluster grouping based on kernel yield under effect of water deficit and full irrigation, the results manifested four major groups of maize hybrids with different genetic constituents were highlighted in the scatter plot, the first group was implicated the hybrid (Medium 791), however the second group included Btaris only. The third group composed of (Cantabpis and Fajr 260), whereas the last group composed of two different hybrids (EsSolito 655 and Dhqan) (Fig. 2). The results displayed the existence of variability among the maize hybrids involved in the study, On the other hand, the results of drought resistance indices variation of some traits of Medium 791 hybrid were inversely related 
to those recorded for Dhqan hybrid, our results are in agreement with those of Bouslama and Schapaugh (1984), Anwer et al. (2011) and Khalili et al. (2012). The results of the cluster analysis, and yield response factor $(\mathrm{Ky})$ and stress indices of six maize hybrids were corresponded due to maize hybrid performance.

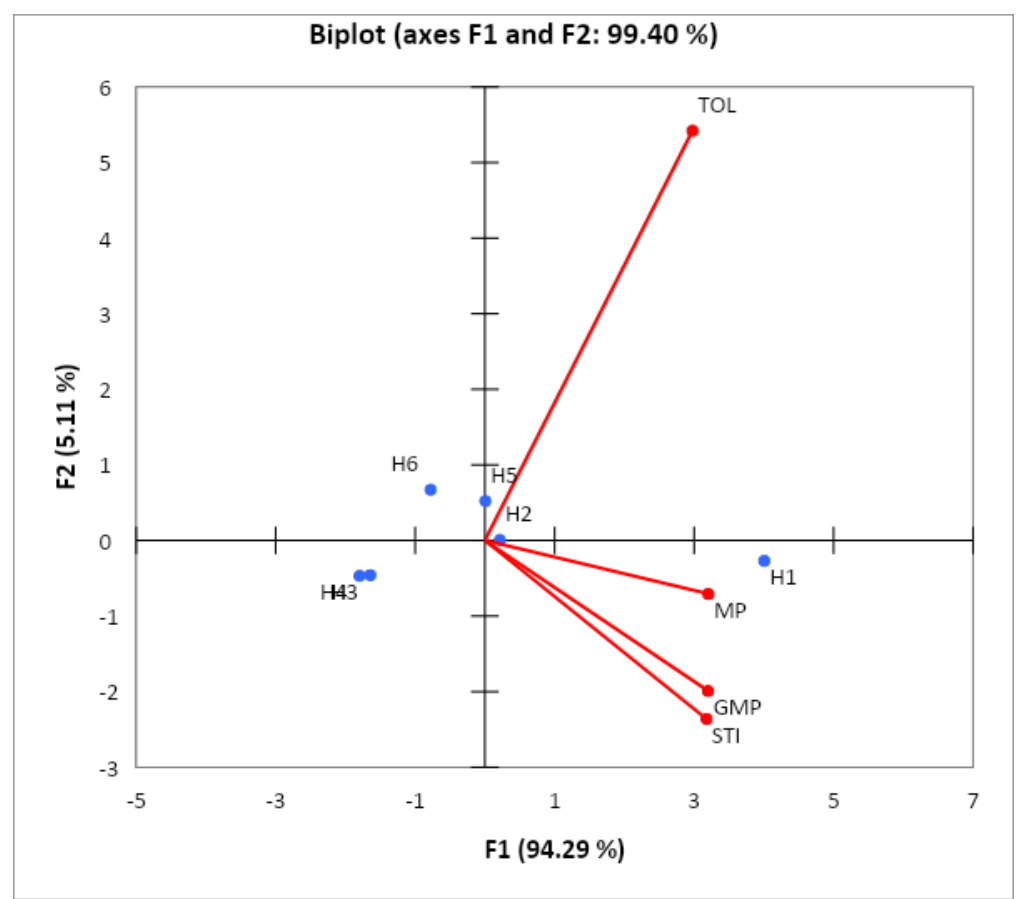

Figure 1. The biplot display of yield in four drought tolerance indices

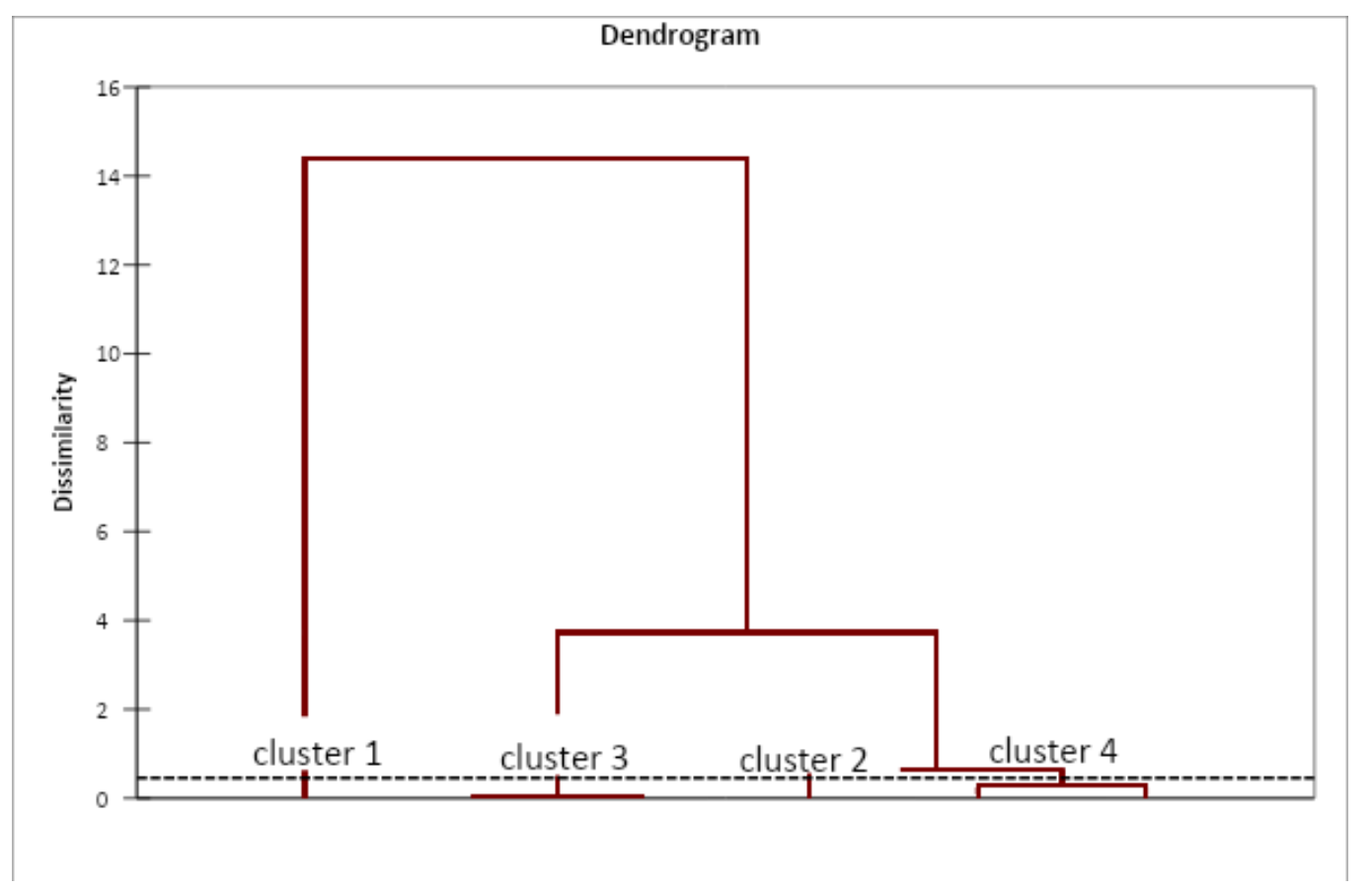

Figure 2. Cluster analysis of maize hybrids depending on drought tolerance indices characters using Euclidean distance and unweighted pair-group method average (UPGMA) 


\section{Conclusions}

The higher means of seasonal evapotranspiration were imperative to the necessity of determining of the yield response factor (Ky) more accurately in different growth stages, included initial, rapid growth, mid season, and late season stages through calculating of adjusted crop coefficient, as well adjusted crop evapotranspiration. The results of Ky in all growth stages were varied with that was reported by FAO no.33. The results of the correlation coefficient between the yield of maize hybrids and stress indices manifested significant correlation with the water stress conditions created with second and third levels of irrigations, furthermore with indices STI, TOL, MP, and GMP. The results of the cluster analysis displayed the existence of variability among the maize hybrids through four major groups of maize hybrids with different genetic constituents were highlighted in the scatter plot, indicating to the (Medium 791) hybrid as a most tolerant hybrid, whereas, the hybrids Es-Solito 655, and Dhqan were the most susceptible hybrids. Although the hybrid Medium 791 with a desirable yield in all conditions is recommendable in a semiarid conditions, further research may be required to be conducted for evaluating the tolerance and susceptibility of maize hybrids.

\section{REFERENCES}

[1] Ahmad, S. Q., Khan, S., Ghaffar, M., Ahmad, F. (2011): Genetic diversity analysis for yield and other parameters in maize (Zea mays L.) genotypes. - Asian J. Agri. Sci. 3(5): 385-388.

[2] Allen, R. G., Pereira, L., Raes, D., Smith, M. (2017): FAO Irrigation and Drainge Paper No.56. Crop Evapotranspiration (guidelines for computing crop water requirements). FAO, Rome.

[3] Anwar, J., Subhani, G. M., Hussain, M., Ahmad, J., Hussain, M., Munir, M. (2011): Drought tolerance indices and thier correlation with yield in exotic wheat genotypes. Pak. J. Bot. 43: 1527-1530.

[4] Bouslama, M., Schapaugh, W. T. (1984): Stress tolerance in soybean. Part 1: Evaluation of three screening techniques for heat and drought tolerance. - Crop Sci J 24: 933-937.

[5] Carvalho, D. F., Neto, D. H. O., Felix, L. F., Guerra, J. G. M., Salvador, C. A. (2016): Yield, water use efficiency, and yield response factor in carrot crop under different irrigation depths. - Ciência Rural, Santa Maria. http://dx.doi.org/10.1590/0103$8478 \mathrm{cr} 20150363$.

[6] Dagdelen, N., Yilmaz, E., Sezgin, F., Gurbuz, T. (2005): Water yield relation and water use efficiency of cotton (Gossypium hirsutum 1.) and second crop corn (Zea mays L.) in western Turkey. - Agricultural Water Management. DOI: 10.1016/j.agwat.2005.05.006.

[7] Darvishzadeh, R., Pirzad, A., Hatami-Maleki, H., Kiani, S. P., Sarrafi, A. (2010): Evaluation of the reaction of sunflower inbred lines and their F1 hybrids to drought conditions using various stress tolerance indices. - Spanish Journal of Agricultural Research 8(4): 1037-1046.

[8] Deryng, D., Conway, D., Kutty, N. R., Price, J., Warren, R. (2014): Global crop yield response to extreme heat stress under multiple climate change futures. - Environ. Res. Lett. 9: 034011.

[9] Dijaman, K., Irmak, S., Rathje, W. R., Martin, D. L., Eisenhauer, D. E. (2013): Maize evapotranspiration, yield production functions, biomass, grain yield, harvest index, and yield response factors under full and limited irrigation. - American Society of Agricultural and Biological Engineers 56(2): 273-293.

[10] Doorenbos, J., Kassam, A. H. (1979): Yield Response to Water. - FAO Irrigation and Drainage paper No. 33. FAO, Rome. 
[11] Doorenbos, J., Kassam, A. H. (1994): Yield Response Factor to water. - FAO Irrigation and Drainage paper no. 33. FAO, Rome.

[12] Eriksson, L., Johansson, E., Kettaneh-Wold, N., Wold, S. (1999): Introduction to Multiand Megavariate Data Analysis Using Projection Methods (PCA \& PLS). - Umetri AB, Umea, Sweden.

[13] Fernandez, G. J. (1992): Effective selection criteria for assessing plant stress tolerance. Proceeding of the International Symposium on Adaptation of Vegetables and other Food Crops in Temperature and Water Stress, Aug 13-16, Taiwan, pp. 257-270.

[14] Greaves, G. E., Wang, Y. (2017): Yield response, water productivity, and seasonal water production functions for maize under deficit irrigation water management in southern Taiwan. - Plant Production Science 20(4): 353-365.

[15] Irandoust, T., Bijanzadeh, E. (2017): Crop water stress index and canopy temperature changes of triticale (X Triticosecale Wittmack) cultivars under irrigation scheduling. Jordan Journal of Agricultural Sciences 13: 745-755.

[16] Khalili, M., Kazemi, M., Moghaddam, A., Shakiba, M. (2004): Evaluation of drought tolerance indices at different growth stages of late-maturing corn genotypes. Proceedings of the 8th Iranian Congress of Crop Science and Breeding, Rasht, Iran, pp. 298.

[17] Khalili, M., Naghavi, M. R., Aboughadareh, A. P., Talebzadeh, S. J. (2012): Evaluating of drought stress tolerance based on selection indices in spring canola cultivars (Brassica napus L.). - Journal of Agricultural Science 4(11).

[18] Khodarahmpour, Z., Choukan, R., Bihamta, M. R. Hervan, E. M. (2011): Determination of the best heat stress tolerance indices in maize (Zea mays L.) inbred lines and hybrids under khuzestan province conditions. - J. Agr. Sci. Tech.13: 111-121.

[19] Kuscu, H., Karasu, A., Ozi, M., Demir, A. O., Turgut, I. (2013): Effect of irrigation amounts applied with drip irrigation on maze evapotranspiration, yield, water use efficiency, and net rreturn in a subhuimed climate. - Turkish Journal of Field Crops 18: 13-19.

[20] Mengu, G. P., Ozgorel, M. (2008): An evaluation of water yield relations in maize (Zea mays L.) in Turkey. - Pakistan J. Biol. Sci. 11: 517-524.

[21] Mitra, J. (2001): Genetics and Genetic improvement of drought resistance in crop plants. - Curr.Sci.80: 758-762.

[22] Moghaddam, A., Hadizadeh, M. H. (2002): Response of corn hybrids and their parental lines to drought using different stress tolerant indices. - Iranian J. Seed and Seedling 18: 255-272.

[23] Nacharchi, M., Kaveh, F., Babazadeh, H., Manshouri, M. (2011): Determination of the yield response factor for field crop deficit irrigation. - African Journal of Agricultural Research 6: 3700-3705.

[24] Papathanasioua, F., Dordasb, C., Gekasb, F., Pankoub, C., Ninoub, E., Mylonasb, I., Tsantarmasc, K., Sistanisa, I., Sinapidouc, E., Lithourgidisd, A., Petrevskaa, J., Papadopoulosa, I., Zouliamise, P., Kargiotidouc, A., Tokatlidisc, I. (2015): The use of stress tolerance indices for the selection of tolerant inbred lines and their correspondent hybrids under normal and water-stress conditions. - Procedia Environmental Sciences 29: 274-275.

[25] Payero, J. O., Tarkalson, D. D., Irmak, S., Davison, D., Petersen, J. L. (2008): Effect of irrigation amounts applied with subsurface drip irrigation on corn evapotranspiration, yield, water use efficiency, and dry matter production in a semiarid climate. Agricultural Water Management 95(8): 895-908.

[26] Rosielle, A. A., Hamblin, J. (1981): Theoretical aspects of selection for yield in stress and non-stress environments. - Crop Sci 21: 943-946.

[27] Steduto, P., Hsiao, T. C., Fereres, E., Raes, D. (2012): Crop Yield Response to Water. FAO, Rome. 
[28] Talebi, R., Fayaz, F., Naji, A. M. (2009): Effective selection criteria for assessing drought stress tolerance in durum wheat (Triticum durum Des). - General and Applied Pl. Physio. 35: 64-74.

[29] Zare, M. (2012): Evaluation of drought tolerance indices for the selection of Iranian barley (Hordeum vulgare) cultivars. - African Journal of Biotechnology 11(93): 1597515981. 